\title{
Increasing Pediatricians' Awareness of the Association between Anal Skin Tags and Earlier Diagnosis of Crohn's Disease
}

\author{
Burton I. Korelitz ${ }^{\mathrm{a}}$ Bernard Partiula $^{\mathrm{b}}$ Kelly Teagle ${ }^{\mathrm{a}}$ Arun Swaminath $^{\mathrm{a}}$ \\ Judy Schneider ${ }^{a}$ Martin Ellington ${ }^{c}$ Guillaume Stoffels ${ }^{d}$ \\ anflammatory Bowel Disease Service, Division of Gastroenterology, Lenox Hill Hospital, New York, NY, USA; \\ ${ }^{b}$ Department of Medicine, Lenox Hill Hospital, New York, NY, USA; ' Department of Pediatrics, Lenox Hill Hospital, \\ New York, NY, USA; ${ }^{d}$ Department of Biostatistics, Lenox Hill Hospital, New York, NY, USA
}

\section{Keywords}

Anal skin tags · Crohn's disease $\cdot$ Earlier diagnosis

\section{Abstract}

Objective: To seek the habits of pediatricians by which anorectal skin tags (AST) of Crohn's disease might be overlooked.Methods: Questionnaires were sent to pediatricians affiliated with the Northwell Health System. Results: Based on the responses, the majority of pediatricians did feel the abdomen of children presenting with abdominal pain or diarrhea but did not spread the buttocks to seek the presence of AST unless there was rectal pain, rectal bleeding, or, in some cases, loose stools. Conclusions: The diagnosis of Crohn's disease could be made earlier when asymptomatic AST are searched for in children with gastrointestinal symptoms. (c) 2018 S. Karger AG, Basel

\section{Introduction}

Gastroenterologists and particularly inflammatory bowel disease clinicians are familiar with the recognition of anorectal skin tags (AST) as a manifestation of Crohn's disease. While their physical characteristics have been described [1-4], research in inflammatory bowel disease has never focused on their significance. Anal and perirectal features such as abscesses, fissures, fistulas, their relationship to other signs and symptoms of $\mathrm{CD}$, and their frequency and surgical management have warranted much more attention since they serve to compromise the quality of life. AST, however, are asymptomatic even when they are large and obviously pathological in their appearance, and when they are found on physical examination they have been present for an indefinite period of time. Examples of skin tags are shown in Figure 1.

Since Crohn's disease presents most often in childhood and AST are already present and have been present for some time before the diagnosis is made, we sought to determine the habits of pediatricians in the search for AST in the hope that this exercise will lead to earlier diagnosis and therapy to prevent progression of the disease

\section{KARGER}

(c) 2018 S. Karger AG, Basel

E-Mail karger@karger.com

www.karger.com/iid
Burton I. Korelitz MD 

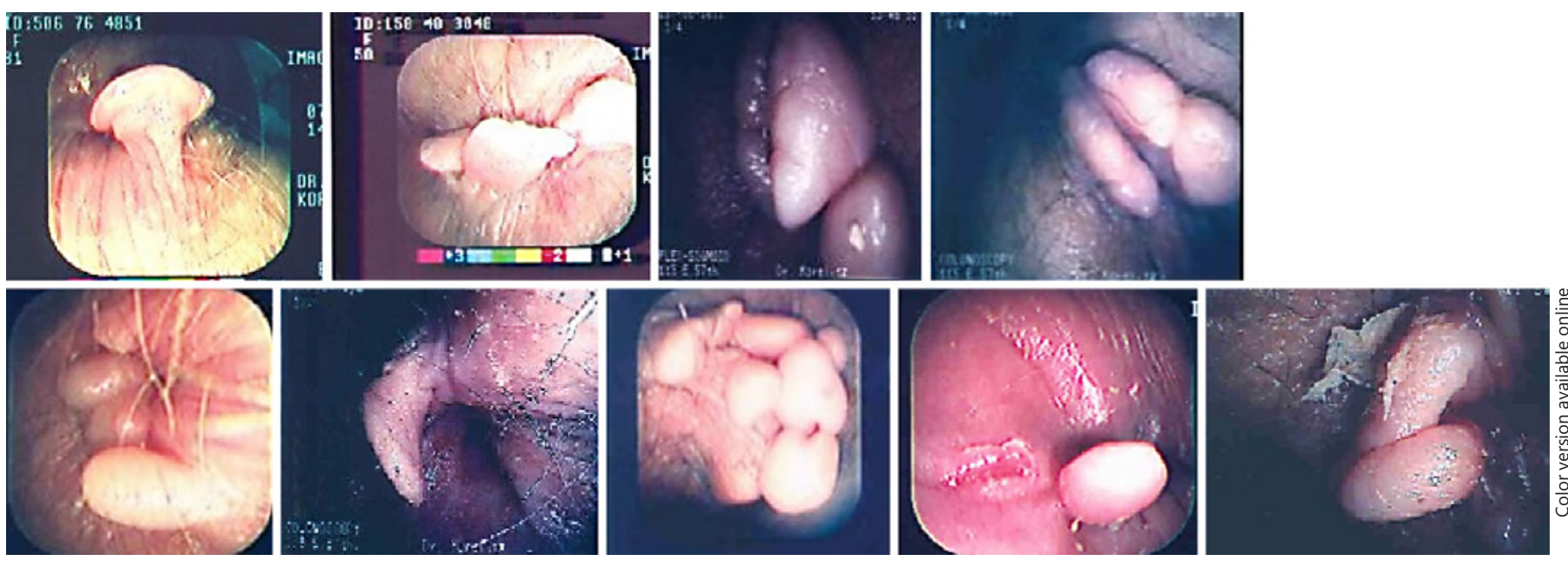

Fig. 1. Characteristic features of anal skin tags.

There were a total number of 23 respondents who were analyzed. All analyses were performed using SAS version 9.4 (SAS Institute, Cary, NC).

- Number of patients seen per month and per year (Question 1) - The median number of patients seen per month and per year was 350 and 4,125, respectively.

- Gl symptoms (Question 2) - The median percentage of patients seen per month with a) rectal bleeding, b) rectal pain or discomfort, or c) diarrhea, abdominal pain or cramps for all respondents was $0.8 \%, 0.4 \%$, and $16.7 \%$, respectively.

- Type of examination (Question 3) - The median percentage of patients who had a) palpation of the abdomen, b) a rectal exam, or c) an inspection of the anus for all respondents was $35.7 \%, 0.3 \%$, and $5.9 \%$, respectively.

- Being familiar with anorectal skin tags (ASTs) and ability to differentiate between ASTs and hemorrhoids (Question 4) All but one respondent was familiar with ASTs. Twenty (i.e., 87\%) considered they could distinguish between ASTs and hemorrhoids.

- Number of patients with hemorrhoids or ASTs among patients with Gl symptoms (Question 5) - The median of reported hemorrhoids was $4 \%$ and of ASTs $3 \%$.

- Management upon finding hemorrhoids (Question 6) and ASTs (Question 7) - 20/23 chose a single management option: observation $61 \%$, referral to a pediatric gastroenterologist $35 \%$, ice and pain control $9 \%$.

- Management of patients with GI symptoms who also had ASTs (Question 8) - Only 9 respondents answered Question 8 in a way that was consistent with their answers in Question 5b. Also, 2 of these 9 respondents did not recall seeing any patient with diarrhea or rectal pain who also had ASTs. All 7 patients were referred to a gastroenterologist or colorectal surgeon or had colonoscopy or flexible sigmoidoscopy.

Fig. 2. Questionnaire for pediatricians.

and destruction of tissue resulting in surgical intervention and recurrences [5].

Accordingly, a questionnaire was sent to all pediatricians enrolled into the Northwell Health System for their answers to pertinent questions to determine their habits in searching for AST and subsequent management (Fig. 2). A secondary goal was to share the resulting information with all pediatricians in the hope of promoting earlier diagnosis and treatment of Crohn's disease in the population where it almost certainly has its beginnings.

Anal Skin Tags, Crohn's Disease, and Earlier Diagnosis

\section{Discussion}

The number of responses was less than hoped for but nevertheless represents a cross-section of busy pediatricians. It is clear that a pediatrician is often overwhelmed with both well visits, frightened children, and concerned parents and does not always have the peace to do a leisurely work-up when there is a new complaint. Nevertheless, when a child presents with rectal bleeding, rectal pain, or abdominal pain and/or diarrhea, a diagnosis 
must be sought. The responses suggest the abdomen will likely be felt under these circumstances, but a rectal examination or even spreading the buttocks to find AST is done much less frequently. The nature of AST contributes to the problem since they do not cause pain and they might be very small; when they are small and painless the differential diagnosis from hemorrhoids can be problematic and they are unlikely to lead to further work-up, and then the possible diagnosis of Crohn's disease is postponed and the underlying bowel inflammation may be progressive. At this stage it has infrequently been the habit of the pediatrician to refer the patient to a pediatric (or adult) gastroenterologist; more often, only when the AST are larger, redder, more waxy, and appearing like "elephant ears" will they be the route to referral. Once the referral has occurred the prognostic significance of the AST is soon recognized and a work-up with colonoscopy and/or bowel imaging will serve to identify the ileitis, the ileocolitis, or the colitis, but in some cases the bowel damage might already be irreversible and subsequently require resection.

The purpose of this study is to call to the attention of pediatricians that Crohn's disease most often begins in childhood and that AST can serve as an early marker of an inflammatory process already initiated in the gastrointestinal tract and to raise the index of suspicion so that the diagnosis may be made much sooner than is currently the case, particularly since immunosuppressive and bi- ological drugs have been so successful in treatment, and that the need for surgical management be eliminated [5].

\section{Acknowledgment}

This study was supported by a grant from the New York Crohn's Foundation.

\section{Disclosure Statement}

None.

References

1 Sandborn WJ, Fazio VW, Feagan BG, Hanauer SB; American Gastroenterological Association Clinical Practice Committee: AGA technical review on perianal Crohn's disease. Gastroenterology 2003;125:1508-1530.

2 Aronoff JS, Korelitz BI, Sohn N, et al: Anorectal Crohn's disease. BioDrugs 2000;13:95105

3 Bonheur JL, Braunstein J, Korelitz BI, Panagopoulos G: Anal skin tags in inflammatory bowel disease: new observations and a clinical review. Inflamm Bowel Dis 2008;14:12361239.

4 Korelitz BI: Anal skin tags: an overlooked indicator of Crohn's disease. J Clin Gastroenterol 2010;44:151-152.

5 Ashton JJ, Harden A, Beattie RM: Pediatric inflammatory bowel disease: improving early diagnosis. Arch Dis Child 2018;103:307-308. 